DOI: https://doi.org/10.47405/mjssh.v5i5.418

\begin{tabular}{|c|c|}
\hline $2 \sqrt{10}$ & Malaysian Journal of Social Sciences and Humanities (MJSSH) \\
\hline $\begin{array}{l}\text { Malaysian Journal of } \\
\text { Socal scionces and }\end{array}$ & Volume 5, Issue 5, May 2020 \\
\hline (MJ-SSH) & e-ISSN : 2504-8562 \\
\hline & $\begin{array}{l}\text { Journal home page: } \\
\text { www.msocialsciences.com }\end{array}$ \\
\hline
\end{tabular}

\title{
Pengetahuan, Sikap dan Kesedaran Pendorong Tingkah Laku Inovasi Pembungkusan Usahawan Mikro
}

\author{
Mahani Amat' ${ }^{1}$, Suraiya Ishak ${ }^{1}$ \\ 1Pusat Pembangunan, Sosial dan Persekitaran, Fakulti Sains Sosial dan Kemanusiaan, Universiti Kebangsaan Malaysia \\ (UKM)
}

Correspondence: Mahani Amat (mahanihalimi@gmail.com.my)

\begin{abstract}
Abstrak
Tingkah laku inovasi pembungkusan didorong oleh faktor pengetahuan, sikap dan kesedaran. Artikel ini bertujuan untuk mengukur tahap faktor pendorong tingkah laku inovasi pembungkusan yang terdiri daripada faktor pengetahuan, sikap dan kesedaran usahawan mikro. Kerangka kajian ini berasaskan kepada Teori Tingkah Laku Terancang. Seramai 40 orang usahawan mikro makanan di negeri Selangor telah dipilih sebagai sampel kajian melalui teknik persampelan rawak sistematik. Instrumen kajian ini merupakan soal selidik dengan enam skala Likert dan mengandungi item-item yang telah disahkan oleh pakar-pakar penilai serta mempunyai nilai kebolehpercayaan yang baik. Data kajian ini dianalisis secara statistik deskriptif iaitu berasaskan nilai min dan peratusan. Dapatan kajian menunjukkan purata peratusan dan nilai min keseluruhan bagi tahap pengetahuan dan kesedaran tingkah laku inovasi pembungkusan adalah tinggi. Malah, usahawan juga bersikap sangat positif untuk melaksanakan inovasi pembungkusan. Kesimpulannya, tingkah laku inovasi pembungkusan usahawan mikro didorong oleh faktor pengetahuan, sikap dan kesedaran setelah mendapat bimbingan agensi.
\end{abstract}

Kata kunci: pengetahuan, sikap, kesedaran, inovasi pembungkusan, usahawan mikro

\section{Knowledge, Attitude and Awareness Driven Micro Entrepreneurs Packaging Innovation Behavior}

\begin{abstract}
Packaging innovation behavior are driven by knowledge, attitude and awareness factors. This article aims to measure the level of knowledge, attitude and awareness factors in packaging innovation behavior. This research framework based on Theory of Planned Behaviour. About 40 micro entrepreneurs in the food industry in Selangor were taken as a sample of this study using simple random sampling techniques. This research instrument was a questionnaire with six-Likert-scale and consisting of items which has been verified by expert subject matters and have a good realibility. The data were analyzed using descriptive statistics which is based on mean value and percentage. The findings of thus study showed that the average of percentages and overall value of mean for the knowledge level and awareness of packaging innovation behavior are high. In fact, entrepreneurs are also very positive in implementing packaging innovations. In conclusion, packaging innovation behavior among micro entrepreneurs should be driven by the knowledge, attitude and awareness factors after receiving guidance from the agency.
\end{abstract}

Keywords: knowledge, attitude, awareness, packaging innovation, micro enterpreneurs 


\section{Pengenalan}

Secara konvesionalnya, pembungkusan menjadi medium penting untuk melindungi produk daripada sebarang kerosakan fizikal mahupun kesan akibat tindakan bahan kimia. Kerosakan ini boleh berlaku di sepanjang rantaian semasa proses penyimpanan, pengendalian, pengangkutan hingga ke pengguna akhir. Namun, perubahan gaya hidup masa kini telah meningkatkan peranan pembungkusan terutamanya dalam pemasaran. Campuran pemasaran telah meletakkan pembungkusan sebagai elemen kelima terpenting selepas produk, harga, promosi dan pengguna. Menurut Khan et al. (2017) pembungkusan masa kini berperanan sebagai alat komunikasi dalam mempengaruhi keputusan pembelian pengguna. Malah, hasil kajian Polyakova (2013) dan Mohebbi (2014) menunjukkan kepentingan reka bentuk pembungkusan seperti grafik, warna, dan maklumat produk berperanan penting dalam mempromosikan produk dan mempengaruhi tingkah laku beli pengguna.

Di samping itu, penampilan reka bentuk pembungkusan dapat membezakan antara produk pesaing dan menyumbang kepada penciptaan nilai terhadap sesuatu produk (Che Mohd Zulkifli \& Anas 2014; Rundh 2016). Sebagai contoh, kanak-kanak memberikan reaksi yang lebih positif dan lebih seronok untuk memilih produk yang mempunyai pembungkusan visual yang lebih menarik berbanding pembungkusan biasa (Dial \& Musher-Eizenman 2020). Dalam konteks tingkah laku pengguna kosmetik pula, pengguna lebih terpengaruh dan lebih tertarik oleh unsur-unsur visual reka bentuk pembungkusan kosmetik seperti bahan pembungkus dan warna pembungkusan berbanding niat asal pembelian (Mohamed et al. 2018). Malah, penampilan pembungkusan berbentuk sampel tidak dipandang enteng oleh pihak pasar raya walaupun semasa peringkat penilaian produk (Anwar 2018). Oleh itu, pengeluar produk terutamanya usahawan mikro perlu memfokuskan inovasi pembungkusan untuk meningkatkan pemasaran produk dan menarik daya pembelian.

Di semua negara, majoriti perusahaan (antara 70\% dan 95\%) adalah perniagaan mikro (OECD 2018). Di Malaysia pula, sebanyak $76.5 \%$ pertumbuhan ekonomi negara adalah disumbangkan oleh perniagaan mikro (SME Corp. Malaysia 2018). Justeru itu, melihat akan kepentingan sumbangan usahawan mikro, terdapat 17 buah kementerian dan lebih 60 buah agensi kerajaan di Malaysia telah dipertanggungjawabkan sebagai agensi pembimbing untuk membantu, memfokuskan dan membangunkan usahawan mikro (SME Corp. Malaysia 2018). Pelbagai program pembangunan usahawan telah disediakan oleh agensi pembimbing seperti kursus dan latihan, pembiayaan, bantuan peralatan, perkongsian teknologi, khidmat nasihat dan lain-lain. Tujuannya adalah bagi membangunkan usahawan agar terus dapat berdaya saing dalam pasaran yang semakin kompetitif. Usaha kerajaan ini akan mudah dicapai sekiranya usahawan mikro bersama-sama menyokong aktiviti yang telah dirancang oleh agensi pembimbing.

Program pembangunan usahawan yang direncanakan oleh agensi pembimbing mampu membantu usahawan terutamanya usahawan mikro untuk meningkatkan perniagaan dengan adanya faktor diri usahawan. Hasil daripada kajian yang dijalankan oleh Tengku Maaidah dan Nor Aishah (2016), model dan kaedah perlaksanaan program seperti ilmu pengurusan kewangan dan bimbingan perniagaan mampu menyelesaikan masalah yang dihadapi oleh usahawan mikro. Kejayaan ini didorong oleh sikap dan pengetahuan usahawan yang membentuk perubahan pemikiran usahawan semasa bimbingan dijalankan (Maisarah \& Sarmila 2017; Tengku Maaidah \& Nor Aishah 2016). Malah, beberapa kajian lepas turut menyatakan bahawa kejayaan perniagaan dan peningkatan prestasi perniagaan adalah didorong oleh latar belakang diri usahawan, kemahiran mengurus perniagaan, kemahiran jaringan, pengalaman pengurusan, pengalaman industri, keadaan ekonomi dan kemahiran perancangan (Azmi et al. 2012; Maisarah \& Sarmila 2017; Muhammad Asri \& Zaimah 2012). Manakala, kajian berkaitan inovasi pula lebih memfokuskan kepada inovasi produk, inovasi proses, inovasi peralatan dan inovasi pemasaran berbanding inovasi pembungkusan (Suraiya et al. 2015; Zaim Shah \& Hartini 2016).

Berdasarkan kepada Teori Tingkah Laku Terancang (Ajzen 1991) (Rajah 1) pula, tingkah laku individu turut dipengaruhi oleh faktor sikap, norma subjektif dan kawalan perilaku yang boleh berlaku dalam 
keadaan sedar setelah mempertimbangkan segala informasi yang tersedia. Peningkatan kesedaran dan sikap adalah disebabkan oleh tingkah laku yang lebih positif (Kollmuss \& Agyeman 2002). Justeru itu, terdapat ruang untuk mengukur tahap faktor pendorong tingkah laku inovasi pembungkusan yang terdiri daripada faktor pengetahuan, sikap dan kesedaran usahawan mikro. Dalam kajian ini sikap dan norma subjektif yang terdiri daripada pengetahuan dan kesedaran adalah diukur. Dapatan kajian ini secara tidak langsung dapat membuktikan bahawa tahap pengetahuan, sikap dan kesedaran usahawan mikro yang mendorong tingkah laku inovasi pembungkusan adalah boleh diukur. Selain itu, kajian ini dapat memberikan manfaat kepada agensi pembimbing dalam merencanakan program pembangunan usahawan terutamanya dalam memfokuskan program inovasi pembungkusan dalam kalangan usahawan mikro di bawah bimbingan agensi.

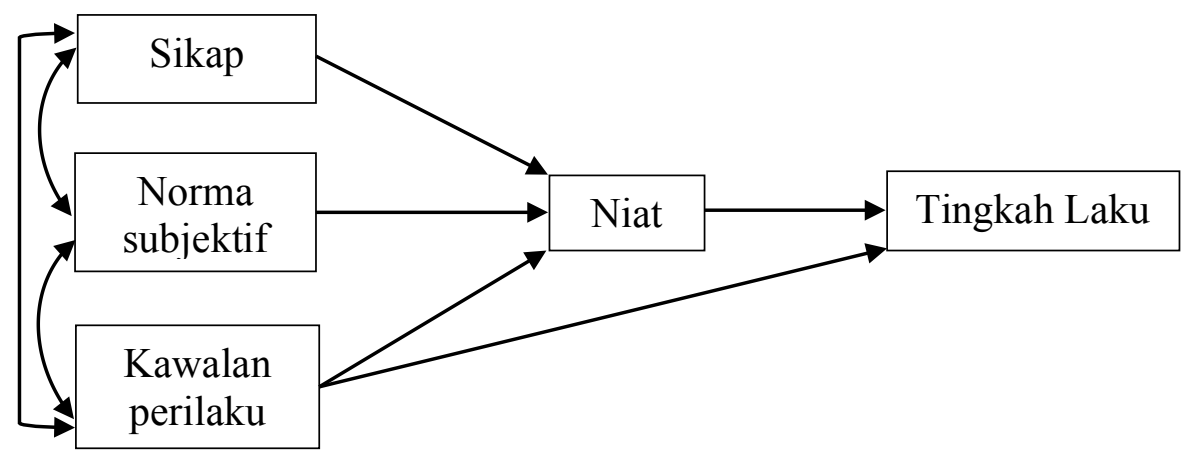

Rajah 1: Teori Tingkah Laku Terancang (Ajzen 1991)

\section{Pernyataan Masalah}

Pada masa ini, hanya $20 \%$ sahaja atau 1,169 produk PKS yang telah berjaya menembusi pasaraya, sedangkan ruang untuk produk PKS di pasaraya adalah sebanyak 30\% telah diperuntukkan (Anon. 2018a). Malah, sebanyak 72.6\% perusahaan mikro tergolong dalam kategori Tahap 2 di bawah Penarafan Daya Saing Perusahaan Mikro untuk Peningkatan (M-CORE) (SME Corp. Malaysia 2018). Peratusan ini menunjukkan perusahaan mikro mempunyai potensi untuk berkembang dan berpeluang untuk memasarkan produk usahawan mikro ke pasaraya. Namun, hasrat ini sukar dicapai berikutan kelemahan kualiti pembungkusan yang tidak mencapai tahap piawaian yang ditetapkan oleh pemilik pasaraya. Masalah pembungkusan yang sering berlaku adalah penggunaan bahan pembungkus yang tidak berkualiti, informasi yang tidak lengkap, reka bentuk dan reka grafik yang tidak menarik, dan kaedah pembungkusan yang kurang sesuai (Ahmad Zaki 2011; Anon. 2014, 2018b). Ekoran permasalahan ini, agensi pembimbing telah menyediakan pelbagai inisiatif untuk meningkatkan kualiti pembungkusan seperti latihan, geran, peralatan, khidmat nasihat dan pembangunan reka bentuk pembungkusan. Hal ini bagi memastikan usahawan mikro di Malaysia berupaya menembusi pasaran di pasaraya dan dapat bersaing dengan pesaing hingga ke pasaran global.

Persoalannya, apakah tahap faktor pendorong tingkah laku inovasi pembungkusan yang terdiri daripada pengetahuan, sikap dan kesedaran usahawan mikro? Justeru itu, objektif artikel ini adalah untuk mengukur tahap faktor pendorong tingkah laku inovasi pembungkusan yang terdiri daripada faktor pengetahuan, sikap dan kesedaran usahawan mikro. Kajian ini penting dilaksanakan agar faktor diri usahawan yang terdiri daripada pengetahuan, sikap dan kesedaran berupaya mendorong tingkah laku inovasi pembungkusan. Kajian literatur jelas menunjukkan untuk meningkatkan pasaran produk dan reputasi perniagaan, penampilan pembungkusan perlu ditambah baik. Oleh itu, tahap pengetahuan, sikap dan kesedaran usahawan yang mendorong tingkah laku inovasi pembungkusan dilihat dan dikaji. 


\section{Kaedah Kajian}

Kajian ini telah dilakukan secara tinjauan. Instrumen soal selidik digunakan untuk tujuan pengumpulan data yang dibahagikan kepada 4 bahagian iaitu bahagian demografi, pengukuran aspek pengetahuan, sikap dan kesedaran. Pengukuran pemboleh ubah tahap pengetahuan, sikap dan kesedaran telah dilakukan menggunkan skala Likert 6 mata terdiri daripada (1) sangat tidak setuju sehingga (6) sangat setuju. Item pernyataan terdiri daripada soal selidik yang diubahsuai berdasarkan kajian-kajian lepas selaras dengan objektif kajian. Instrumen ini telah disahkan oleh 4 orang pakar penilai dalam bidang keusahawanan dan perniagaan, teknologi pembungkusan makanan, dan pembangunan sumber manusia dan penilaian latihan, 2 orang pegawai agensi di agensi pembimbing dan 2 orang usahawan dalam bidang perusahaan makanan. Nilai kebolehpercayaan Cronbach's Alpha seperti dalam Jadual 1. Menurut Hair et al. (2007) nilai Cronbach's Alpha yang melebihi 0.7 dikategorikan sebagai item yang mempunyai kebolehpercayaan yang baik.

Jadual 1: Nilai kebolehpercayaan Cronbach's Alpha

\begin{tabular}{lccc}
\hline Pemboleh ubah & Cronbach's Alpha & Bilangan Item & Konsistensi Dalaman \\
\hline Pengetahuan & 0.923 & 8 & Cemerlang \\
Sikap & 0.924 & 8 & Cemerlang \\
Kesedaran & 0.915 & 7 & Cemerlang \\
\hline
\end{tabular}

Kajian ini telah dijalankan di negeri Selangor dan sampel kajian melibatkan 40 orang usahawan mikro makanan yang telah mendapat bimbingan pembungkusan daripada agensi seperti Jabatan Pertanian, MARDI, FAMA dan UPEN Selangor. Justifikasi pemilihan agensi berdasarkan kepada peranan aktif agensi untuk penambahbaikan pembungkusan produk makanan usahawan mikro. Kaedah pensampelan menggunakan teknik pensampelan rawak sistematik bagi mengelakkan bias. Data kajian diperoleh melalui edaran borang soal selidik kepada usahawan secara pertemuan bersemuka, melalui pos dan pengisian secara maya menggunakan google dokumen. Bagi meningkatkan maklum balas, usahawan dihubungi dan diberikan peringatan mesra berulang kali serta diberikan e-book berkaitan pemasaran kepada usahawan yang telah memberikan maklum balas.

Dalam kajian ini, analisis deskriptif digunakan bagi menjawab objektif kajian. Tahap pengetahuan, sikap dan kesedaran yang dikaji adalah menggunakan peratusan, frekuensi dan min seterusnya analisis tahap interpretasi diambil kira daripada nilai enam mata. Jadual 2 menunjukkan interpretasi min yang digunakan dalam dapatan kajian bagi pengukuran pengetahuan dan kesedaran. Manakala, Jadual 3 menunjukkan interpretasi min yang digunakan dalam dapatan kajian bagi pengukuran sikap.

Jadual 2: Interpretasi min bagi pengetahuan dan kesedaran

\begin{tabular}{cc}
\hline Julat Min & Interpretasi \\
\hline $0.00-2.49$ & Rendah \\
$2.50-4.49$ & Sederhana \\
$4.50-6.00$ & Tinggi \\
\hline
\end{tabular}

Sumber: Jeff Pruchnic et al. (2018)

Jadual 3: Interpretasi min bagi sikap

\begin{tabular}{cc}
\hline Julat Min & Interpretasi \\
\hline $0.00-1.50$ & Sangat Negatif \\
$1.51-3.00$ & Negatif \\
$3.01-4.50$ & Positif \\
$4.51-6.00$ & Sangat Positif \\
\hline
\end{tabular}

Sumber: Adaptasi dan ubahsuai dari Jeff Pruchnic et al. (2018) 
DOI: https://doi.org/10.47405/mjssh.v5i5.418

\section{Dapatan Kajian dan Perbincangan}

\section{Pengetahuan}

Jadual 4 menunjukkan analisis tahap pengetahuan bagi setiap item pengetahuan inovasi pembungkusan usahawan di bawah bimbingan agensi. Hasil dapatan kajian menunjukkan kesemua lapan item tersebut mempunyai skor min yang tinggi. Item yang mempunyai skor yang tertinggi adalah inovasi pembungkusan menggambarkan identiti tersendiri terhadap sesuatu produk $(\mathrm{min}=5.40)$ dengan jumlah peratus responden setuju dan sangat setuju adalah sebanyak 95.0\%. Diikuti dengan inovasi pembungkusan dapat dilaksanakan jika ada ilmu pengetahuan $(\min =5.30)$ dengan jumlah peratus responden yang setuju dan sangat setuju adalah sebanyak $90.0 \%$ dan sedikit setuju $10.0 \%$. Manakala, inovasi pembungkusan dapat meningkatkan ketahanan produk $(\min =5.25)$ dengan jumlah peratus responden yang setuju dan sangat setuju adalah sebanyak $92.5 \%$, sedikit setuju $5.0 \%$ dan kurang setuju $2.5 \%$.

Item bagi inovasi pembungkusan membantu produk kekal dalam pasaran $(\min =5.20)$ pula menunjukkan setuju dan sangat setuju adalah sebanyak $85 \%$ dan sedikit setuju $15.0 \%$. Seterusnya, item inovasi pembungkusan adalah menambahbaik reka bentuk pembungkusan $(\mathrm{min}=5.20)$ setuju dan sangat setuju adalah sebanyak $87.5 \%$ dan sedikit setuju $12.5 \%$, inovasi pembungkusan adalah menambahbaik informasi maklumat pada pembungkusan $(\min =5.15)$ setuju dan sangat setuju adalah sebanyak $87.5 \%$, sedikit setuju $7.5 \%$ dan kurang setuju 5.0\%. Item inovasi pembungkusan adalah menambahbaik kaedah pembungkusan $(\min =5.08)$ setuju dan sangat setuju adalah sebanyak $80.0 \%$, sedikit setuju $17.5 \%$ dan kurang setuju $2.5 \%$. Item yang memberikan min terendah adalah inovasi pembungkusan adalah menambahbaik penggunaan jenis bahan pembungkus $(\mathrm{min}=5.00)$ setuju dan sangat setuju adalah sebanyak $82.5 \%$, sedikit setuju $12.5 \%$ dan kurang setuju $5.0 \%$.

Oleh itu, dapat diringkaskan bahawa item 6 iaitu "Inovasi pembungkusan menggambarkan identiti tersendiri terhadap sesuatu produk" mencatatkan min yang tertinggi iaitu 5.40 dan mencatatkan jumlah sebanyak $95.0 \%$ responden yang setuju dan sangat setuju pada item tersebut. Manakala item 1 iaitu "Inovasi pembungkusan adalah menambahbaik penggunaan jenis bahan pembungkus" mencatatkan min yang terendah iaitu 5.00 dan mencatatkan jumlah sebanyak $72.5 \%$ responden yang setuju dan sangat setuju pada item tersebut dan $27.5 \%$ responden yang sedikit setuju dan kurang setuju dengan pernyataan item yang diberikan.. Secara keseluruhannya, skor pengetahuan usahawan mengenai inovasi pembungkusan adalah tinggi $(\mathrm{min}=5.20)$ dengan jumlah purata peratus bagi responden yang sangat setuju dan setuju adalah $87.5 \%$ dan hanya $12.5 \%$ yang sedikit setuju dan kurang setuju.

Jadual 4: Analisis tahap pengetahuan inovasi pembungkusan bagi setiap pernyataan

\begin{tabular}{|c|c|c|c|c|c|c|}
\hline No & Pernyataan & $\begin{array}{l}\text { KS } \\
(\%)\end{array}$ & $\begin{array}{l}\mathrm{SeS} \\
(\%)\end{array}$ & $\begin{array}{c}\mathrm{S} \\
(\%)\end{array}$ & $\begin{array}{l}\text { SS } \\
(\%)\end{array}$ & Min \\
\hline 1 & $\begin{array}{l}\text { Inovasi pembungkusan adalah menambahbaik } \\
\text { penggunaan jenis bahan pembungkus. }\end{array}$ & 5.0 & 12.5 & 60.0 & 22.5 & 5.00 \\
\hline 2 & $\begin{array}{l}\text { Inovasi pembungkusan adalah menambahbaik } \\
\text { kaedah pembungkusan. }\end{array}$ & 2.5 & 17.5 & 50.0 & 30.0 & 5.08 \\
\hline 3 & $\begin{array}{l}\text { Inovasi pembungkusan adalah menambahbaik } \\
\text { reka bentuk pembungkusan. }\end{array}$ & 0.0 & 12.5 & 55.0 & 32.5 & 5.20 \\
\hline 4 & $\begin{array}{l}\text { Inovasi pembungkusan adalah menambahbaik } \\
\text { informasi maklumat pada pembungkusan. }\end{array}$ & 5.0 & 7.5 & 55.0 & 32.5 & 5.15 \\
\hline 5 & $\begin{array}{l}\text { Inovasi pembungkusan dapat meningkatkan } \\
\text { ketahanan produk. }\end{array}$ & 2.5 & 5.0 & 57.5 & 35.0 & 5.25 \\
\hline 6 & $\begin{array}{l}\text { Inovasi pembungkusan menggambarkan identiti } \\
\text { tersendiri terhadap sesuatu produk. }\end{array}$ & 0.0 & 5.0 & 50.0 & 45.0 & 5.40 \\
\hline 7 & Inovasi pembungkusan membantu produk kekal & 0.0 & 15.0 & 50.0 & 35.0 & 5.20 \\
\hline
\end{tabular}


DOI: https://doi.org/10.47405/mjssh.v5i5.418

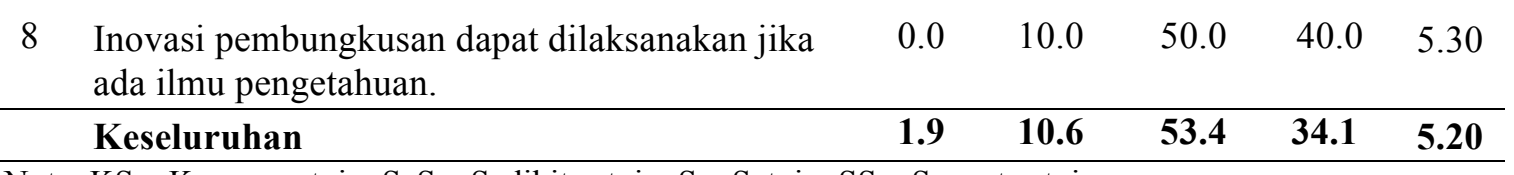

Nota: KS - Kurang setuju, SeS - Sedikit setuju, S - Setuju, SS - Sangat setuju

Penemuan ini menunjukkan bahawa selepas menyertai program pembungkusan bimbingan agensi, usahawan mikro mempunyai tahap pengetahuan yang tinggi mengenai inovasi pembungkusan. Malah, usahawan juga bersetuju bahawa inovasi pembungkusan dapat dilaksanakan jika mempunyai pengetahuan. Usahawan mikro juga memahami akan kepentingan inovasi pembungkusan yang menggambarkan identiti tersendiri, dapat meningkatkan ketahanan produk dan membantu produk untuk kekal dalam pasaran. Dapatan ini jelas sebagaimana yang dibincangkan oleh Raffo et al. (2000) yang menyatakan bahawa pengetahuan yang diperolehi daripada agensi pembimbing berupaya memberikan pendekatan yang lebih naturalistik untuk menghasilkan pembungkusan yang lebih berinovasi. Malah, Anwar (2018) dan Johan et al. (2018) turut menyatakan bahawa pengetahuan berupaya ditingkatkan hasil daripada kursus dan latihan yang diikuti, dan pengalaman lalu. Oleh itu, kejayaan inovasi pembungkusan yang dilakukan adalah didorong oleh kefahaman pengetahuan dan keupayaan usahawan mikro untuk menggemblengkan segala sumber yang dimiliki dengan baik.

Walau bagaimanapun, dapatan kajian juga menunjukkan usahawan mikro kurang memahami keperluan untuk menambahbaik informasi maklumat, menambahbaik kaedah pembungkusan dan menambahbaik penggunaan jenis bahan pembungkus. Penambahbaikan informasi, kaedah dan jenis bahan pembungkus juga merupakan sebahagian daripada inovasi yang boleh dilakukan pada pembungkusan. Justeru itu, agensi pembimbing perlu menambahbaik program pembungkusan sedia ada dengan memberi penekanan yang lebih kepada aspek informasi, kaedah dan jenis bahan pembungkus. Adanya kefahaman yang lebih berkaitan inovasi pembungkusan, maka, tingkah laku inovasi pembungkusan dalam kalangan usahawan mikro juga berupaya ditingkatkan. Penemuan ini membuktikan bahawa pembangunan modal insan yang dirancang secara intensif oleh agensi pembimbing berupaya menggalakkan tingkah laku inovasi dalam perniagaan (Hasliza et al. 2015; Vixathep \& Phonvisay 2019).

\section{Sikap}

Jadual 5 menunjukkan skor min dan peratusan bagi setiap item sikap usahawan mengenai inovasi pembungkusan yang diukur oleh lapan item. Kesemua lapan item tersebut mempunyai skor yang sangat positif. Item yang mempunyai skor yang tertinggi adalah saya berimaginasi untuk menghasilkan pembungkusan yang menarik $(\mathrm{min}=5.62)$ dan diikuti dengan saya berusaha mencari peluang untuk melakukan inovasi pembungkusan $(\mathrm{min}=5.58)$. Kedua-dua item berkenaan menunjukkan jumlah peratus responden setuju dan sangat setuju adalah sebanyak 97.5\%. Manakala, item bagi saya mahu menghasilkan inovasi pembungkusan yang berbeza dari orang lain $(\mathrm{min}=5.57)$ dan item saya beranggapan inovasi pembungkusan akan memberikan keuntungan $(\mathrm{min}=5.55)$ keduaduanya menunjukkan jumlah peratus responden setuju dan sangat setuju adalah sebanyak $95.0 \%$ dan sedikit setuju $5.0 \%$.

Seterusnya, saya seorang yang fleksibel dalam melakukan inovasi pembungkusan $(\min =5.48)$ dengan jumlah peratus responden setuju dan sangat setuju adalah sebanyak $97.5 \%$ dan sedikit setuju $2.5 \%$. Item saya bermotivasi tinggi dalam melakukan inovasi pembungkusan $(\mathrm{min}=5.42)$ dengan jumlah peratus responden setuju dan sangat setuju adalah sebanyak $95.0 \%$ dan sedikit setuju $5.0 \%$. Manakala, item saya positif melakukan inovasi terhadap pembungkusan produk $(\mathrm{min}=5.40)$ dengan jumlah peratus responden setuju dan sangat setuju adalah sebanyak $97.5 \%$ dan sedikit setuju $2.5 \%$. Min terendah adalah saya sanggup mengambil risiko bagi memastikan inovasi pembungkusan dapat dilaksanakan $(\mathrm{min}=5.28)$ dengan jumlah peratus responden setuju dan sangat setuju adalah sebanyak $90.0 \%$, sedikit setuju $7.5 \%$ dan kurang setuju $2.5 \%$. Secara keseluruhannya, skor sikap usahawan mengenai amalan inovasi pembungkusan adalah sangat positif $(\min =5.49)$ dengan jumlah peratus responden setuju dan sangat setuju adalah sebanyak $95.5 \%$, sedikit setuju $4.2 \%$ dan kurang setuju $0.3 \%$. 
DOI: https://doi.org/10.47405/mjssh.v5i5.418

Jadual 5: Analisis tahap sikap inovasi pembungkusan bagi setiap pernyataan

\begin{tabular}{|c|c|c|c|c|c|c|}
\hline No & Pernyataan & $\begin{array}{l}\text { KS } \\
(\%)\end{array}$ & $\begin{array}{l}\mathrm{SeS} \\
(\%)\end{array}$ & $\begin{array}{c}\mathrm{S} \\
(\%)\end{array}$ & $\begin{array}{c}\text { SS } \\
(\%)\end{array}$ & Min \\
\hline 1 & $\begin{array}{l}\text { Saya positif melakukan inovasi terhadap } \\
\text { pembungkusan produk. }\end{array}$ & 0.0 & 2.5 & 55.0 & 42.5 & 5.40 \\
\hline 2 & $\begin{array}{l}\text { Saya mahu menghasilkan inovasi pembungkusan } \\
\text { yang berbeza dari orang lain. }\end{array}$ & 0.0 & 5.0 & 32.5 & 62.5 & 5.57 \\
\hline 3 & $\begin{array}{l}\text { Saya sanggup mengambil risiko bagi memastikan } \\
\text { inovasi pembungkusan dapat dilaksanakan. }\end{array}$ & 2.5 & 7.5 & 50.0 & 40.0 & 5.28 \\
\hline 4 & $\begin{array}{l}\text { Saya berusaha mencari peluang untuk melakukan } \\
\text { inovasi pembungkusan. }\end{array}$ & 0.0 & 2.5 & 37.5 & 60.0 & 5.58 \\
\hline 5 & $\begin{array}{l}\text { Saya berimaginasi untuk menghasilkan } \\
\text { pembungkusan yang menarik. }\end{array}$ & 0.0 & 2.5 & 32.5 & 65.0 & 5.62 \\
\hline 6 & $\begin{array}{l}\text { Saya seorang yang fleksibel dalam melakukan } \\
\text { inovasi pembungkusan. }\end{array}$ & 0.0 & 2.5 & 47.5 & 50.0 & 5.48 \\
\hline 7 & $\begin{array}{l}\text { Saya bermotivasi tinggi dalam melakukan inovasi } \\
\text { pembungkusan. }\end{array}$ & 0.0 & 5.0 & 47.5 & 47.5 & 5.42 \\
\hline 8 & $\begin{array}{l}\text { Saya beranggapan inovasi pembungkusan akan } \\
\text { memberikan keuntungan. }\end{array}$ & 0.0 & 5.0 & 35.0 & 60.0 & 5.55 \\
\hline & Keseluruhan & 0.3 & 4.2 & 42.1 & 53.4 & 5.49 \\
\hline
\end{tabular}

Nota: KS- Kurang setuju, SeS-Sedikit setuju, S-Setuju, SS-Sangat setuju

Penemuan ini menunjukkan bahawa selepas menyertai program pembungkusan bimbingan agensi, usahawan mikro mempunyai sikap yang sangat positif untuk melakukan inovasi pembungkusan. Usahawan mikro mempunyai daya imaginasi yang tinggi dan berusaha mencari peluang untuk melakukan inovasi pembungkusan setelah mendapat bimbingan agensi. Malah, usahawan mikro juga bersedia untuk menghasilkan inovasi pembungkusan yang berbeza dari orang lain dan beranggapan bahawa inovasi pembungkusan mampu menjana keuntungan. Kecenderungan usahawan miro untuk bertindak, menyokong dan melakukan inovasi pembungkusan didorong oleh sikap yang positif (Hall 2002; Johan et al. 2018). Justeru itu, dapatan ini jelas menunjukkan bahawa tingkah laku inovasi pembungkusan dalam kalangan usahawan mikro adalah didorong oleh sikap positif usahawan sebagaimana yang dikemukakan dalam Teori Tingkah Laku Terancang (Ajzen 1991). Malah, usahawan yang memberikan komitmen yang tinggi untuk melaksanakan inovasi pembungkusan akan mencapai kejayaan dalam perniagaan.

Dapatan kajian menunjukkan usahawan mikro masih bersikap kurang sanggup mengambil risiko bagi memastikan inovasi pembungkusan dapat dilaksanakan walaupun telah mendapat bimbingan agensi. Usahawan mikro perlu mempunyai sikap bersedia untuk menerima perubahan dan sentiasa bersedia untuk menanggung risiko. Hal ini jelas menunjukkan bahawa ciri-ciri seseorang usahawan itu untuk berjaya adalah masih rendah sebagaimana pandangan yang dikemukakan oleh Mahathir (2012) yang menyatakan majoriti usahawan mikro (Bumiputera) bukanlah golongan yang mempunyai sikap sanggup mengambil risiko. Walau bagaimanapun, sikap terhadap tingkah laku inovasi pembungkusan boleh berubah melalui program bimbingan dan latihan oleh agensi pembimbing (Buerah \& Zoolhilmi 2015; Harris \& Gibson 2008; Muhammad Ali 2003).

\section{Kesedaran}

Jadual 6 menunjukkan skor min dan peratusan bagi setiap item kesedaran usahawan mengenai kepentingan inovasi pembungkusan yang diukur oleh tujuh item. Hasil kajian menunjukkan kesemua tujuh item tersebut mempunyai skor yang tinggi. Item yang mempunyai skor yang tertinggi adalah pembungkusan produk saya perlu ditambahbaik jika hendak memasuki pasaran antarabangsa $(\mathrm{min}=$ 5.82) dengan jumlah peratus responden setuju dan sangat setuju adalah sebanyak $100 \%$. Diikuti dengan pembungkusan produk saya perlu ditambahbaik jika hendak memasuki pasar raya $(\mathrm{min}=5.78)$ 
dan item inovasi pembungkusan adalah strategi pemasaran $(\mathrm{min}=5.75)$ dengan kedua-dua jumlah peratus responden setuju dan sangat setuju adalah sebanyak $97.5 \%$ dan sedikit setuju $2.5 \%$.

Manakala, item inovasi pembungkusan dapat meningkatkan daya saing $(\mathrm{min}=5.73)$ juga menunjukkan jumlah peratus responden setuju dan sangat setuju adalah sebanyak $97.5 \%$ dan sedikit setuju $2.5 \%$.

Seterusnya, inovasi pembungkusan dapat meningkatkan prestasi perniagaan $(\mathrm{min}=5.73)$ menunjukkan jumlah peratus responden setuju dan sangat setuju adalah sebanyak $100 \%$. Item saya perlu melakukan inovasi pembungkusan apabila berhadapan dengan persaingan $(\mathrm{min}=5.65)$ pula menunjukkan jumlah peratus responden setuju dan sangat setuju adalah sebanyak $97.5 \%$ dan sedikit setuju $2.5 \%$. Min terendah adalah pengguna membeli kerana pembungkusan yang berinovasi $(\mathrm{min}=$ 5.55) menunjukkan jumlah peratus responden setuju dan sangat setuju adalah sebanyak $95 \%$ dan sedikit setuju 5\%. Secara keseluruhannya, skor kesedaran usahawan mengenai kepentingan inovasi pembungkusan adalah tinggi $(\min =5.71)$ dengan jumlah peratus responden setuju dan sangat setuju adalah sebanyak $97.9 \%$ dan sedikit setuju $2.1 \%$.

Jadual 6: Analisis tahap kesedaran usahawan mengenai kepentingan inovasi pembungkusan bagi setiap pernyataan

\begin{tabular}{|c|c|c|c|c|c|}
\hline No & Pernyataan & $\begin{array}{l}\text { SeS } \\
(\%)\end{array}$ & $\begin{array}{c}\mathrm{S} \\
(\%)\end{array}$ & $\begin{array}{l}\text { SS } \\
(\%)\end{array}$ & Min \\
\hline 1 & $\begin{array}{l}\text { Pembungkusan produk saya perlu ditambahbaik jika } \\
\text { hendak memasuki pasar raya. }\end{array}$ & 2.5 & 17.5 & 80.0 & 5.78 \\
\hline 2 & $\begin{array}{l}\text { Pembungkusan produk saya perlu ditambahbaik jika } \\
\text { hendak memasuki pasaran antarabangsa. }\end{array}$ & 0.0 & 17.5 & 82.5 & 5.82 \\
\hline 3 & Inovasi pembungkusan dapat meningkatkan daya saing. & 2.5 & 22.5 & 75.0 & 5.73 \\
\hline 4 & $\begin{array}{l}\text { Inovasi pembungkusan dapat meningkatkan prestasi } \\
\text { perniagaan. }\end{array}$ & 0.0 & 27.5 & 72.5 & 5.73 \\
\hline 5 & Inovasi pembungkusan adalah strategi pemasaran. & 2.5 & 20.0 & 77.5 & 5.75 \\
\hline 6 & $\begin{array}{l}\text { Pengguna membeli kerana pembungkusan yang } \\
\text { berinovasi. }\end{array}$ & 5.0 & 35.0 & 60.0 & 5.55 \\
\hline \multirow[t]{2}{*}{7} & $\begin{array}{l}\text { Saya perlu melakukan inovasi pembungkusan apabila } \\
\text { berhadapan dengan persaingan. }\end{array}$ & 2.5 & 30.0 & 67.5 & 5.65 \\
\hline & Keseluruhan & 2.1 & 24.3 & 73.6 & 5.71 \\
\hline
\end{tabular}

Penemuan ini menunjukkan bahawa selepas menyertai program pembungkusan bimbingan agensi, usahawan mikro mempunyai tahap kesedaran yang tinggi mengenai kepentingan inovasi pembungkusan. Malah, usahawan mikro sedar akan kepentingan inovasi pembungkusan sebagai strategi pemasaran untuk tujuan pasaran antarabangsa dan pasar raya. Dapatan ini telah mengembangkan idea Pathak (2014) yang menyatakan produk yang mempunyai pembungkusan baharu berupaya menembusi pasaran baharu. Selain itu, usahawan mikro juga sedar bahawa inovasi pembungkusan dapat meningkatkan prestasi perniagaan dan meningkatkan daya saing pasaran terutamanya apabila berhadapan dengan pesaing. Tingkah laku pembelian pengguna dipengaruhi oleh penampilan pembungkusan yang dapat membezakannya dengan produk pesaing (Benachenhou et al. 2018). Justeru itu, penampilan pembungkusan yang baharu, maka, strategi pemasaran juga adalah perlu berbeza dan disesuaikan dengan keadaan semasa. Agensi pembimbing perlu meningkatkan kesedaran usahawan mikro mengenai perubahan strategi pemasaran yang perlu dilakukan seiring dengan inovasi pembungkusan. Kesedaran ini seiring dengan adanya pengetahuan dan sikap yang dimiliki usahawan mikro mengenai kepentingan inovasi pembungkusan.

Walau bagaimanapun, usahawan mikro perlu meningkatkan tahap kesedaran akan kepentingan inovasi pembungkusan dari sudut pengguna. Hal ini kerana banyak kajian lepas telah membuktikan bahawa inovasi pembungkusan berupaya menarik tingkah laku pembelian dan berupaya menggamit emosi dalam kalangan pengguna (Benachenhou et al. 2018; Bilovodska et al. 2016; Imiru 2017). Oleh itu, agensi pembimbing perlu tingkatkan lebih banyak program berkaitan inovasi pembungkusan dengan 
pendekatan yang lebih kreatif agar usahawan mikro mempunyai kesedaran yang lebih mengenai kepentingan inovasi pembungkusan dalam pemasaran. Dapatan ini jelas menunjukkan bahawa tingkah laku inovasi pembungkusan dalam kalangan usahawan mikro adalah didorong oleh adanya kesedaran dan kecenderungan niat untuk melakukan inovasi pembungkusan sebagaimana yang dikemukakan dalam Teori Tingkah Laku Terancang (Ajzen 1991).

Justeru, tingkah laku usahawan tidak mudah diubah jika hanya ada kesedaran niat semata-mata (Nasrudin et al. 2014), tetapi, tingkah laku inovasi pembungkusan boleh dilakukan dengan adanya pengetahuan dan sikap positif usahawan mikro untuk melakukan inovasi pembungkusan. Usahawan mikro perlu meningkatkan pengetahuan inovasi pembungkusan sama ada daripada agensi pembimbing atau secara tidak formal. Malah, usahawan mikro juga perlu sentiasa bersikap positif untuk menanggung risiko dan menerima perubahan pembungkusan. Agensi pembimbing juga perlu memainkan peranan lebih dalam menggalakkan inovasi pembungkusan melalui khidmat bimbingan yang lebih berkesan dan sesuai dengan keperluan semasa usahawan mikro. Sebagai contoh, penambahbaikan modul pembungkusan dengan memasukkan modul berkaitan inovasi pembungkusan.

\section{Kesimpulan}

Secara keseluruhan, tahap pengetahuan dan kesedaran usahawan dalam tingkah laku inovasi pembungkusan adalah berada pada tahap yang tinggi dan mempunyai sikap yang sangat positif selepas mendapat bimbingan agensi. Tingkah laku inovasi pembungkusan dapat dilaksanakan dengan baik sekiranya usahawan mendapat bimbingan daripada agensi. Hal ini kerana bimbingan agensi dalam inovasi pembungkusan dapat meningkatkan pengetahuan dan kesedaran usahawan serta membentuk sikap yang positif. Faktor diri usahawan yang terdiri daripada pengetahuan, sikap dan kesedaran berupaya mendorong tingkah laku inovasi pembungkusan seperti mana dalam Teori Tingkahlaku Terancang (TPB) (Ajzen 1991). Teori ini meramalkan tingkah laku boleh dirancang dengan beranggapan bahawa perilaku manusia berlaku dalam keadaan yang sedar dan didorong oleh faktor diri usahawan. Oleh itu, usahawan perlu sentiasa berusaha meningkatkan pengetahuan inovasi pembungkusan melalui pembelajaran secara formal mahupun tidak formal. Di samping itu, usahawan perlu kekal positif dan sedar akan kepentingan inovasi pembungkusan. Faktor diri usahawan ini akan memberikan impak yang positif untuk penghasilan pembungkusan yang lebih berinovasi. Cadangan kajian pada masa akan datang adalah menganalisis hubungan faktor pengetahuan, sikap dan kesedaran inovasi pembungkusan terhadap tingkah laku inovasi pembungkusan.

\section{Rujukan}

Ahmad Zaki, I. (2011). Formula usahawan berjaya. Edisi ke-1. Utusan Publications \& Distributors Sdn Bhd.

Ajzen, I. (1991). The Theory of Planned Behavior. Organizational Behavior and Human Decision Processes 50(2): 179-211.

Anwar, N.A. (2018). Amalan pengurusan kewangan, strategi pemasaran, masalah dan kejayaan usahawan PKS bumiputera. Thesis.Universiti Kebangsaan Malaysia

Anon. (2014). Giant tidak pinggir produk usahawan IKS. Utusan Online, 29 September. Kota Kinabalu.

Anon. (2018a). Pasar raya diminta beri ruang PKS jual produk. Berita Harian, 6. Putrajaya.

Anon. (2018b). Jaga kualiti produk. Harian Metro.

Azmi, A.M, Nik Hairi, O., Lee. K.Y. (2012). Faktor kritikal kejayaan usahawan dalam perniagaan. eBANGI. Jurnal Sains Sosial dan Kemanusiaan 7(1):34-45.

Benachenhou, S.M., Guerrich, B. \& Moussaoui, Z. (2018). The effect of packaging elements on purchase intention: case study of Algerian customers. Management Science Letters 8: 217-224.

Bilovodska, O.A., Klisinski, J., Molybog, M.A., Bilovodska, O.A., Klisinski, J. \& Molybog, M.A. (2016). Packaging in the process of innovative activities as a part of goods distribution management. Marketing and Management of Innovations 4: 31-42. 
DOI: https://doi.org/10.47405/mjssh.v5i5.418

Buerah, T. \& Zoolhilmi, A. (2015). Pengaruh faktor latar belakang terhadap orientasi sikap keusahawanan dalam kalangan usahawan belia Bumiputera Muslim. Akademika 85(2): 29-43.

Che Mohd Zulkifli, C.O. \& Anas, T. (2014). The marketing of small and medium enterprise (SME) products based on food processing. European Journal of Business and Social Sciences 3(5): 7687.

Dial, L.A. \& Musher-Eizenman, D.R. (2020). Power of packaging: Evaluations of packaged fruits and vegetables by school-age children in the U.S. Appetite, 148.

Hair, J., Money, A., Page, M. \& Samouel, P. (2007). Research Methods for Business. United States of America: John Wiley \& Sons, Ltd.

Hall, H. (2002). Sharing Capability: The development of a framework to investigate knowledge sharing in distributed organizations. In proceedings of the. Third European Conference on Organizational Knowledge, Learning and Capabilities, 5-6 April. Athens.

Harris, M.L. \& Gibson, S.G. (2008). Examining the entrepreneurial attitudes of US business students. Education+Training 50(7): 568-581.

Hasliza, A.H., Noor Hazlina, A., Ramayah, T., Haniruzila, H., Taghizadeh, S.K. \& Marini Nurbanum, M. (2015). Towards an innovation culture: Enhancing innovative performance of Malaysian SMEs. Academic Journal of Interdisciplinary Studies 4(2): 85-94.

Imiru, G.A. (2017). The effect of packaging attributes on consumer buying decision behavior in major commercial cities in Ethiopia. International Journal of Marketing Studies 9(6): 43.

Johan, J., Nur Faraeein, Z.A., Jabil, M., Nur Izzah Nabilah, H., Siti Hairah, T. \& Alexander, C.C. (2018). Faktor penentu kejayaan usahawan kuih tradisional di Daerah Papar, Sabah. GEOGRAFIA OnlineTM Malaysian Journal of Society and Space 14 1(1): 142-157.

Khan, G., Khan, F., Khan, G. \& Khan, F. (2017). The role of packaging and labelling in determining "halalness": an exploratory study of Muslims in two countries. International Journal Islamic Marketing and Branding 2(2): 85-99.

Kollmuss, A. \& Agyeman, J. (2002). Mind the gap: Why do people act environmentally and what are the barriers to pro-environmental behavior? Environmental Education Research 8(3): 239-260.

Mahathir, M. (2012). Doktor Umum: Memoir Tun Dr. Mahathir Mohammad. Petaling Jaya, Selangor: $\mathrm{MPH}$.

Maisarah C.A., \& Sarmila M.S., (2017). Belia Dan Keusahawanan Tani : Kajian Faktor-Faktor Yang Mempengaruhi Penglibatan Belia Sebagai Usahawan Tani Di Pasir Puteh, Kelantan. Jurnal Wacana Sarjana, 1(1):1-18.

Mohamed, N.B.A., Medina, I.G. \& Romo, Z.G. (2018). The effect of cosmetics packaging design on consumers' purchase decisions. Indian Journal of Marketing 48(12): 50-61.

Mohebbi, B. (2014). The art of packaging: An investigation into the role of color in packaging, marketing, and branding. International Journal of Organizational Leadership 3(2): 92-102.

Muhamad Asri A.G., \& Zaimah Darawi (2012). Transformasi dan Prestasi Perniagaan Usahawan Melayu Perusahaan Kecil dan Sederhana (PKS) di Johor Bahru, Prosiding PERKEM VII, Jilid 1 (2012) $696-708$.

Muhammad Ali, H. (2003). Bisnes Satu Cabang Jihad: Pembudayaan Bisnes untuk Survival. Kuala Lumpur: Utusan Publications \& Distributors.

Nasrudin, N., Rostam, K. \& Che Rose, R.A. (2014). Persepsi penduduk Shah Alam terhadap dasar pengangkutan dan kesediaan mengguna pengangkutan mampan. Malaysian Journal of Society and Space 10(2): 133-142.

OECD. (2018). Entrepreneurship at a Glance 2018 Highlights https://www.oecd.org/sdd/businessstats/EAG-2018-Highlights.pdf

Pathak, A. (2014). The cognitive power of product packaging. Journal of Business and Management (IOSR-JBM) 16(7): 61-64.

Polyakova, K. (2013). Packaging Design as a Marketing Tool and Desire to Purchase. Thesis. Saimaa University of Applied Science.

Raffo, C., Lovatt, A., Banks, M. \& O’Connor, J. (2000). Teaching and learning entrepreneurship for micro and small businesses in the cultural industries sector. Education + Training 42(6): 356365 .

Rundh, B. (2016). The role of packaging within marketing and value creation. British Food Journal 118(10): 2491-2511.

SME Corp. Malaysia. (2018). Laporan Tahunan SME Corp. Malaysia: Permulaan Baharu. 
DOI: https://doi.org/10.47405/mjssh.v5i5.418

Suraiya, I., Abd Hair, A., Mohd Yusof, H., Ahmad Raflis, C.O., Sarmila, M.S., Suhana, S., Zaimah, R. \& Azima, A.M. (2015). Penelitian tingkah laku inovasi firma makanan halal kecil di Malaysia: Satu analisis tentatif. GEOGRAFIA OnlineTM Malaysian Journal of Society and Space 11(2): 64-76.

Tengku Maaidah \& Nor Aishah, B. (2016). Keberkesanan Program Latihan Usahawan Mikro Dalam Membantu Usahawan Bumiputra Islam. Jurnal Reflektika 11(2):59-69.

Vixathep, S. \& Phonvisay, A. (2019). Human capital, innovation and entrepreneurship in micro and small businesses in Laos. Dlm. Matsunaga, N. (pnyt). Innovation in Developing Countries hlm. 99-121. Kobe University, KobeJapan: Springer, Singapore.

Zaim Shah, A. \& Hartini, A. (2016). Inovasi dalam Perusahaan Kecil dan Sederhana (PKS) pembuatan makanan \& minumam. Journal of Global Business and Social Entrepreneurship 1(1): $79-88$. 